\title{
METODOLOGIAS ATIVAS NO ENSINO SUPERIOR: A ARTICULAÇÃO DA RESOLUÇÃO DE SITUAÇÕES PROBLEMA COM O ENSINO POR MEIO DE PROJETOS EM PRÁTICA
}

ACTIVE METHODOLOGIES IN HIGHER EDUCATION: THE ARTICULATION OF THE

RESOLUTION OF SITUATIONS PROBLEM WITH THE TEACHING BY PROJECTS IN PRACTICE

\author{
DINIZ, João Fábio ${ }^{1}$ (Docente dos cursos de Licenciatura - UNIFEOB) \\ joao.diniz@unifeob.edu.br
}

RESUMO. O presente artigo visa discutir a importância das metodologias ativas no ensino superior no contexto atual, no qual o modelo em que o professor era pensando como um mero transmissor de conteúdos se tornou obsoleto. Com efeito, busca-se apresentar duas das metodologias ativas - a aprendizagem através da resolução de situações problema e a aprendizagem por projetos -, e mostrar com ambas podem ser trabalhadas de maneira conjunta para sustentar práticas pedagógicas que realmente sejam capazes de utilizar os conteúdos como matérias primas para a construção de habilidades e competências aptas a levar o futuro egresso ao papel de protagonista em sua atuação profissional. Para tanto, operou-se com a definição conceitual de tais metodologias e com a análise de duas práticas pedagógicas que se basearam na conjugação das mesmas: uma desenvolvida no curso presencial de Licenciatura em Matemática na UNIFEOB e outra no curso online de Pedagogia da mesma instituição.

Palavras-chave: metodologias ativas de ensino, aprendizagem baseada em problemas, aprendizagem baseada em projetos, protagonismo do aluno.

ABSTRACT. This article aims to discuss the importance of current active methodologies in high education. That model which the teacher was just a content transmitter has become obsolete. In fact, we seek to present two of the active methodologies - learning through problem-solving and project-learning - and to show how they both can perform together to sustain pedagogical practices that really can be able to use the content as supplies for skills construction and competences to take the future graduated to the role of central character in their professional career. To do so, we worked with the conceptual definition of such methodologies and with the analysis of two pedagogical practices based on their conjugation: one developed in the attendance course of Degree in Mathematics in UNIFEOB and another in the online course of Pedagogy of the same institution

Keywords: active teaching methodologies, problem-based-learning, project-based-learning,-learner's protagonism.

\section{INTRODUÇÃO}

Uma maneira adequada de introduzir a discussão que se pretende aqui é através da descrição de uma situação, de um "causo", se quisermos, que ocorreu por volta de seis a sete anos atrás em uma instituição de ensino superior no sul do Estado de São Paulo. Naquele período, houvera uma melhoria da internet disponibilizada para os alunos via wifi. Em um primeiro momento, o sinal permanecia ligado mesmo durante o período das aulas, o que, evidentemente, poderia causar dispersão dos alunos. Mas não era esse o problema que atraía 


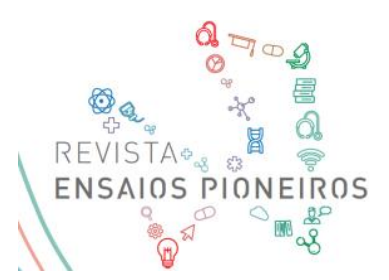

mais reclamações na sala dos professores: no tradicional curso de Administração da faculdade, as queixas giravam em torno da ideia de que os alunos ficavam constantemente checando online as informações que eram expostas pelos docentes, por vezes as questionando, o que parecia criar um ambiente de desconforto e mesmo de insegurança. Podemos dizer que, implícita ou explicitamente, o que é colocado em xeque em uma situação como essa é aquele modelo pedagógico dito tradicional, no qual o professor detém a informação e o aluno não, sendo destinado àquele o pomposo papel de anunciador da verdade dos conteúdos de cada disciplina.

Uma vez que a informação passa a ser acessível por outras fontes, quiçá mesmo mais precisas e mais inteligíveis para os alunos, esse modelo entra em colapso progressivo.

Ao mesmo tempo que esse tipo de situação ainda é presente e patente em uma ampla gama de universidades e faculdades brasileiras, muitos esforços têm também sido realizados no sentido de desenvolver estratégias didáticas mais adaptadas à preparação de profissionais realmente capacitados para a realidade atual. Para tanto, é fundamental a ideia de que saber o conteúdo não é suficiente, é necessário transformar esse saber em algo dinâmico: em habilidades e competências fundamentadas nos conteúdos que serão, elas sim, a base para uma boa atuação profissional. É precisamente de acordo com essa perspectiva que o ensino por meio de problemas tem se destacado como uma das alternativas às formas pedagógicas tradicionais. No meio educacional brasileiro, a instrução através da resolução de problemas tem sido gradativamente mais utilizada: nos primeiros anos do século XXI, verifica-se a ampliação de seu emprego em todos os níveis do sistema educacional, particularmente em cursos superiores nas mais diversas áreas do saber. Esse panorama retrata uma busca por concepções e metodologias de ensino que possibilitem a composição de práticas pedagógicas orientadas pela ideia do aluno enquanto sujeito ativo no processo de ensino e aprendizagem. Uma das principais metodologias problematizadoras que se inserem nessa linha de ação é justamente a chamada aprendizagem baseada em problemas (PBL, do inglês problem-based-learning) (RIBEIRO, 2008).

Essa metodologia encontra-se entre aquelas que se tem nomeado de metodologias ativas no ensino. Uma das características diferenciais de tais metodologias é a busca pela construção de sujeitos autônomos, dotados não apenas do conhecimento do conteúdo abordado, mas também de habilidades e competências que lhes possibilitem colocar em ação seus novos saberes, em conluio com aqueles que já possuíam em sua vivência enquanto indivíduos dotados de uma subjetividade singular, a fim de resolver problemas e desenvolver projetos de intervenção perante uma vasta gama de possibilidades que se lhes apresentará em sua carreira profissional (BERBEL, 2012). É no contexto dessa vertente teórica que se desenvolve a ideia de que uma boa prática pedagógica é aquela que é dotada de um elemento desafiador: ao se estabelecer um desafio para que se cumpra uma atividade que abarca conhecimentos e habilidades múltiplos que precisam ser conciliados para que se dê cabo da tarefa, constrói-se um ambiente realmente dialógico, no qual as interações a) professor/tutor e aluno e b) aluno e aluno assumem uma dimensão colaborativa e harmônica. Totalmente congruente com essa ideia é o desenvolvimento de atividades alicerçadas pela proposição das chamadas situações problema. Perrenaud \& Thurler (2009) as definem como situações didáticas nas quais o sujeito tem uma tarefa que ele somente poderá realizar se mobilizar conteúdos para efetuar a aprendizagem de uma maneira ativa e autônoma.

As situações problema podem engendrar uma grande variedade de práticas pedagógicas no ensino superior; podem, ainda, associar-se a outra das metodologias ativas de ensino: a chamada aprendizagem baseada em projetos (PBL, do inglês, project-based-learning). A partir dessa associação, o elemento desafiador de que se falou acima se coloca não apenas a cada 
indivíduo separadamente, mas sim a um grupo que buscará conjugar saberes de maneira crítica e sinérgica para, em conjunto, elaborar um projeto de atuação, ou de intervenção, que vise exatamente cumprir o esperado perante a situação problema apresentada. De acordo com Bender (2015), um dos principais definidores da metodologia de ensino por projetos, também aqui o que se espera é promover nos alunos uma ação mais efetiva nos processos de aquisição do conhecimento. Ao propor temáticas de interesse do estudante, uma vez que posicionadas no contexto mesmo da sua provável atuação enquanto egresso, torna-se mais natural a passagem da atividade do professor enquanto apenas um provedor de conhecimentos para aquela na qual ele se consolida como um facilitador - um apontador de atalhos para os caminhos que os estudantes vão trilhando com as suas próprias pernas. É importante salientar que os projetos a serem desenvolvidos devem ser, via de regra, trabalhados em grupos de estudantes. Nesse sentido, a metodologia de projetos é extremamente valiosa, uma vez que a processualidade que lhe é característica estabelece um vínculo colaborativo entre os alunos de maneira que os saberes e as ações passíveis de serem realizadas de acordo com o escopo do projeto vão se cumulando em interações significativas; interações essas que vão dando maturidade progressiva à apreensão dos saberes e à sua materialização em habilidades e competências (BENDER, 2015).

Nessa conjuntura própria das metodologias ativas, que visam, como vimos, instituir um tipo de processo educacional no qual os alunos desempenhem um papel ativo e autônomo na sua formação, surge então uma ideia que vem sido bastante discutida atualmente: a do aluno enquanto protagonista do processo de ensino e aprendizagem (BERBEL, 2012). O aluno que consegue completar a sua formação de maneira a ascender a um papel de fato proeminente no processo de sua capacitação profissional com todas as chances será também um profissional capaz de atuar como protagonista em sua área. Para que isso se consolide, no entanto, é essencial que sejam desenvolvidas competências específicas, como a criatividade, a empatia e a capacidade de trabalhar em equipe de maneira cooperativa (LOVATO, YIRULA, \& FRANZIM, 2017). Nesse sentido, a conjugação das duas metodologias ativas descritas parece compor uma estratégia extremamente adequada.

O objetivo deste trabalho é descrever detalhadamente duas práticas pedagógicas desenvolvidas na UNIFEOB que operaram exatamente com a busca de articulação desses dois expedientes inscritos nas metodologias ativas: a aprendizagem por meio da resolução de situação problema e o ensino baseado em projetos; uma das práticas teve curso na Licenciatura em Matemática na modalidade presencial e a outra está sendo desenvolvida na graduação online em Pedagogia. Para cumprir tal objetivo, que podemos chamar de objetivo geral, é necessário dar cabo de outros dois, mais específicos: compreender no que consistem de fato as duas metodologias em questão e buscar determinar de que maneira elas podem ser vetores para a construção da autonomia do aluno universitário; e associar coerentemente a descrição das práticas mencionadas com as definições conceituais das metodologias; ou seja, evidenciar como tais práticas realmente se filiam às bases teóricas anteriormente definidas.

Nesse sentido, o trabalho se justifica por buscar conjugar teorias educacionais de vanguarda com práticas realizadas no âmbito de uma Universidade de relevância em sua região (a região Centro-leste do estado de São Paulo), cujo projeto pedagógico se volta justamente para a edificação de habilidades e competências a partir da utilização das metodologias ativas. Além disso, é relevante notar que um dos intuitos do artigo é demonstrar que a conjugação das duas estratégias ativas de ensino mencionadas pode ser uma estratégia profícua tanto no ensino presencial como na modalidade à distância. 


\section{DESENVOLVIMENTO}

\section{A resolução de situações problema no ensino superior: a teoria como base para a prática}

Visando situar de maneira mais apropriada o horizonte no qual se constrói a estratégia pedagógica do ensino através das situações problema, vale partir de uma concepção de um autor extremamente relevante para o pensamento pedagógico não apenas no Brasil: Paulo Freire. Segundo ele, na educação voltada para adultos, dentre os quais podemos considerar evidentemente os cursandos do ensino superior, a mola propulsora da aprendizagem se dá exatamente no afã pela superação de desafios, pela resolução de problemas e pela aglutinação dos novos saberes com os conhecimentos e experiências prévias do indivíduo (grifo nosso) (FREIRE, 1996). Analisando mais detidamente a passagem acima, podemos notar que a superação de desafios é algo claramente concebível a partir da proposição de um problema prático que se coloca ao discente; proposto tal desafio, será então o momento do educando lançar mão dos novos saberes que processualmente vem adquirindo na graduação para procurar estabelecer uma linha de atuação objetiva de acordo com a conjuntura interposta pela situação problema. No intuito de definir então tal linha de ação, será necessário articular os saberes prévios e os saberes novos que se cristalizam ao se associar àqueles, e os saberes assim constituídos às estratégias práticas - às habilidades e competências. Ou seja, será mister articular o saber com o saber fazer. Neste ponto, é útil nos determos em uma passagem de Berbel (2012) que discorre sobre a interpretação de Moacir Gadotti acerca da obra freiriana:

Gadotti (2001) salienta duas grandes contribuições de Paulo Freire para o pensamento pedagógico brasileiro no século XX. Uma delas é a contribuição à teoria dialética do conhecimento, para a qual a melhor maneira de refletir é pensar a prática e retornar a ela para transformá-la". Freire sugere pensar o concreto, a realidade, e não pensar pensamentos. A outra é a categoria pedagógica da conscientização, visando, por meio da educação, à formação da autonomia intelectual do cidadão para intervir sobre a realidade. A educação, para Freire, não é neutra, mas sempre um ato político (BERBEL, 2012, p. 30).

Ambas as contribuições descritas por Gadotti (2001 APUD BERBEL, 2012, p.30) são bastante esclarecedoras acerca das bases sobre as quais se ergue a eficácia pedagógica das situações problema. Quando Freire aponta a necessidade de não pensar pensamentos, e sim pensar o concreto, o que está em foco é exatamente a ideia de que os conteúdos disciplinares desconexos das suas aplicações práticas não são capazes de preparar o indivíduo para uma atuação concreta no mundo real. Já quando ele faz menção à ideia de conscientização - de tomada de consciência -, estabelece-se a ideia de que ao se educar substantivamente, o indivíduo se torna apto a intervir na realidade a partir da sua formação. Nesse ponto, é importante mencionar que essas intervenções, como fica claro no final do trecho transcrito, no mais das vezes para Freire são pensadas em um contexto político de transformação social. No presente trabalho, o foco é na atuação profissional fundamentada pela capacitação empreendida no processo de ensino e aprendizagem. Seja como for, a partir da coadunação das duas perspectivas, fica clara a necessidade de uma pedagogia que esteja solidamente ancorada na busca da formação de um indivíduo que seja capaz de intervir apropriadamente nas realidades com as quais se deparará em sua vida de egresso.

Ao se apresentar uma situação problema passível de ser vivenciada no dia a dia de sua área do saber, será que realmente se articula uma prática pedagógica capaz de capacitar o 


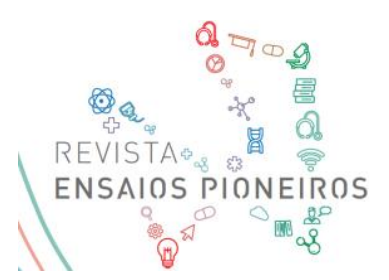

http://ensaiospioneiros.usf.edu.br

indivíduo com os saberes dinâmicos - com as habilidades e competências - que lhes possibilitarão um agir autônomo?

Para estabelecer elementos que nos permitam responder essa indagação com mais acurácia, vejamos como as situações problema na aprendizagem são definidas em um trabalho que é referência no interior do tema (PERRENAUD \& THURLER, 2009). De acordo com a construção da argumentação dos autores, todos nós nos deparamos com diversas situações problema em nosso dia a dia; para resolvê-las, estamos sempre mobilizando recursos cognitivos e alterando hábitos práticos; estamos agindo de acordo com o nosso saber e com o nosso saber fazer. São os desafios constantes com os quais nos deparamos não apenas em nossa vida profissional mas também em nossa vida pessoal. Para que a elaboração de situações problema seja de fato eficaz no contexto da Educação, Perrenaud \& Thurler (2009) apontam que é essencial que se considere com muita atenção quem é o público alvo com o qual se trabalha. As situações que nos desafiam em nosso cotidiano se nos colocam dessa maneira pois segundo a nossa vivência, o nosso imaginário, elas aparecem como relevantes, como necessárias de resolução. No momento de elaborar as situações problema no contexto do ensino superior, é essencial que o educador se pergunte: quem são esses alunos? Qual o seu perfil? Qual a sua área do saber e como posso agir para capacitá-los para a mesma? Quais são as habilidades e competências que eles precisam desenvolver a partir deste ou daquele conteúdo? De que forma tais conteúdos podem ser trabalhados de maneira conjunta com o exercício da criatividade, da empatia e da capacidade de trabalhar em equipe harmonicamente?

Resumindo, é essencial que o educador tenha a sensibilidade para criar situações problema que sejam realmente pertinentes no cenário específico em que a dinâmica de aprendizagem irá se inscrever - cenário esse que pode ser pensado a partir do conjunto das respostas para as indagações enunciadas acima. Um grande e variado leque de práticas pedagógicas baseadas na proposição de situações problema pode ser desenvolvido; isso não garante que tais práticas obterão êxito. Os dois grandes diferenciais para tanto, como apontam Perrenaud \& Thurler (2009), são exatamente a adequação da problemática à construção das habilidades e competências relevantes para a formação profissional de cada área de acordo com seus conteúdos; e a capacidade da situação problema em efetivamente engajar os jovens a serem atores ativos de sua aprendizagem - ou seja, sua capacidade de realmente se constituir como um desafio.

\section{O ensino baseado em projetos como um instrumento valioso para o saber especializado}

Um exemplo simples, mas que pode ser ilustrativo no contexto da compreensão acerca de como as situações problema devem se constituir para encetar práticas significativas no processo de ensino e aprendizagem, é o das operações básicas na Educação Fundamental I. Em um primeiro momento, as crianças devem compreender conceitualmente como se efetuam as quatro operações; posteriormente, é comum que os professores busquem fazer com que tais operações sejam entendidas em ocorrências do cotidiano, e isso é realizado através de situações problema. Tomemos o caso da subtração: após compreender como calcular numericamente a diferença entre dois valores, os alunos em geral se depararão com aqueles "problemas" em que a subtração numérica se torna visível em situações de seu cotidiano. Um exemplo seria: "você tinha doze balas, mas resolveu dar ao seu irmão cinco delas; com quantas você ficou após dálas a ele?" Uma situação problema simples, que faz com que o aluno visualize o funcionamento da subtração a partir de uma dimensão concreta. Após o esforço cognitivo de compreender de que forma o conteúdo matemático se aplica na resolução de uma série de pequenos problemas que são facilmente inteligíveis por se associarem à realidade de seu dia a dia, podemos dizer 
que os alunos desenvolvem a habilidade de utilizar a abstração numérica associada à diferença entre valores para melhor compreender a realidade quantitativa da subtração de elementos reais - e a competência para melhor intervir nessa realidade a partir do novo saber apreendido.

No exemplo citado acima, podemos dizer que o emprego da situação problema nessa etapa da Educação Básica pode ser considerado realmente valioso por conseguir construir a ponte entre o saber e o saber fazer. É nesse sentido que devemos ponderar a eficácia de uma prática estipulada com base em uma situação problema. Seria o caso, então, de se perguntar: como a utilização das situações problema pode ser realmente benéfica para a formação no ensino superior? Uma reflexão nesse sentido deve primeiramente considerar todas as questões mencionadas na seção anterior, mas o caminho apontado aqui é o de que uma forma particularmente vantajosa de utilizá-las nos cursos de graduação é a de articulá-las à metodologia de ensino por projetos. Para tanto, vejamos no que consiste e de que forma é trabalhada tal metodologia.

Bender (2015) considera a metodologia por projetos uma ponte para a educação do futuro. Segundo esse autor, essa prática pedagógica é capaz de descortinar um mundo novo que se abre para o ensino, num formato empolgante e inovador no qual os alunos participam ativamente ao selecionar boa parte de suas tarefas e serem motivados por situações do mundo real. Vejamos uma passagem na qual as estratégias envolvidas com essa prática estão bem sintetizadas:

\footnotetext{
Para o desenvolvimento de um plano de trabalho docente voltado para a pedagogia de projetos, é necessário que o educador reflita a educação numa perspectiva de situações que facilitem o processo de construção do conhecimento e de desenvolvimento de habilidades básicas importantes para o estudante. É importante que o professor domine, pelo menos, os conhecimentos de sua área de atuação para poder relacionálos com as outras áreas do conhecimento, refletir e planejar como coordenar informações e articular diferentes pontos de vista, bem como estimular o trabalho em equipe, despertando o prazer pela pesquisa, pelo diálogo, respeito mútuo, cooperação, proporcionando condições para que os alunos conquistem autonomia para a resolução de problemas (TOYOHARA, SENA, ARAÚJO, \& AKAMATSU, 2010, p. 5).
}

A primeira parte da citação acima se refere a uma perspectiva deveras relevante, comum às metodologias ativas de ensino: a ideia de que o conhecimento do conteúdo deve sempre ser pensada como uma matéria prima para a construção e o desenvolvimento de habilidades práticas específicas de cada área do saber. Já na segunda metade da mesma, alguns dos aspectos diferenciais desse tipo de metodologia são abordados de maneira bastante precisa. A base para a instituição de tais aspectos está vinculada ao estímulo ao trabalho em grupo; como vimos, a metodologia por projetos opera com a ideia de que os alunos formarão grupos para construir um trabalho, que será o produto da prática e poderá ter diversos formatos de acordo com a área do saber, os conteúdos, as habilidades e as competências com as quais se operará. Isso possibilita interações significativas, nas quais o diálogo, o respeito mútuo e a colaboração entre os participantes do grupo se posicionam de maneira a constituir um ambiente extremamente favorável à construção da autonomia do estudante.

Nesse sentido, é relevante notar que a interação aluno/aluno é algo excepcionalmente válido no desenvolvimento de práticas pedagógicas. Muitas vezes certos conteúdos serão mais facilmente compreendidos por um aluno ao ver como um ou alguns de seus colegas pensa (m) a respeito dos mesmos. Isso ocorre pois o imaginário, o vocabulário e a própria visão de mundo dos estudantes no mais das vezes se assemelham mais do que o que ocorre na relação professor/tutor e aluno. É nessa perspectiva que reside aliás a justificativa para a elaboração de outra das chamadas metodologias ativas, a instrução por pares (peer instruction) (MAZUR, 
2015). Dessa maneira, podemos concluir que uma estratégia que se fundamente na conciliação das duas práticas, se bem articulada no contexto das necessidades pedagógicas envolvidas com a transformação do saber no saber fazer, pode estabelecer um ambiente no qual a concretude da intervenção na realidade e a colaboração significativa nas relações professor/tutor e aluno e aluno e aluno realmente concorram para que o discente seja alçado ao lugar de protagonista de sua formação profissional.

Moreira, Lemos \& Sacarmocin (1998) apontam que para que a metodologia de projetos seja bem-sucedida, é essencial que o educador tenha uma ideia bastante clara dos objetivos almejados. Para esses autores, o envolvimento do aluno florescerá de acordo com o interesse que o propósito do projeto e a maneira de desenvolver o produto final do mesmo lhe causarem. Dessa forma, é possível concluir que existe uma base teórica sólida que sustenta a possibilidade de imbricação das duas estratégias no contexto do ensino superior. Agora vejamos se é possível mesurar a validade de tal conjugação em práticas de ensino realmente levadas a cabo em cursos de graduação.

\section{Novas tecnologias na Educação Matemática e as metodologias ativas}

A primeira das práticas a ser abordada vem sendo trabalhada desde o ano de $2016 \mathrm{com}$ os quintos módulos do curso de Licenciatura em Matemática da UNIFEOB. Na instituição em questão, os cursos de graduação operam com um P.I., um projeto integrado que visa articular os conteúdos de todas as disciplinas cursadas em um determinando semestre na composição de um produto final que deve ser desenvolvido em grupos. Para tanto, estabelece-se um objetivo que é exposto aos alunos e que pode ter a forma de uma situação problema. No caso do projeto em questão, ele é, com efeito, desenvolvido a partir de uma situação problema. Vejamos.

No quinto módulo, os alunos cursam duas disciplinas que tem carga horária de 160 horas: Álgebra Linear e Álgebra e Geometria Analítica, e uma disciplina que tem carga horária de 80 horas, Novas Tecnologias na Educação. O projeto integrado visa associar os conteúdos de todas as disciplinas na elaboração de um produto final que, espera-se, seja relevante para a formação dos educandos a partir de sua realidade enquanto profissionais após a graduação. Um curso de licenciatura é um curso de formação de professores, de maneira que sua capacitação tem que necessariamente ser pensada a partir da realidade da prática educativa na Educação Básica. No módulo em questão, a disciplina que tem uma orientação mais diretamente voltada às práticas docentes é exatamente a de Novas tecnologias na Educação, de modo que foi decidido que a mesma seria a responsável pela articulação dos conteúdos na proposição do projeto integrado. Para tanto, foi desenvolvida a seguinte situação problema:

De que forma podemos construir em grupos um plano pedagógico para uma sequência didática que vise operar com algum dos conteúdos das disciplinas de Álgebra Linear ou de Álgebra e Geometria Analítica de forma dinâmica e dialógica a partir da utilização do software de Educação Matemática Geogebra?

Os cinco temas que são sorteados entre os grupos são os seguintes: matrizes, transformação linear, equação da reta, parábola e vetores. É importante perceber que o projeto trabalha com uma perspectiva que é muito importante para os alunos enquanto futuros professores: a apreciação dos temas no Ensino Superior, da forma que eles os acompanham na graduação em Matemática, é bastante denso e específico, e por vezes complexo. É essencial que o futuro professor saiba que no contexto da Educação Básica é necessário ajustar o conteúdo ao público com o qual se trabalhará: na elaboração dos planos, é fundamental que os alunos compreendam como fazê-lo, e isso é construído processualmente através das discussões interativas entre professor/aluno e aluno/aluno. 


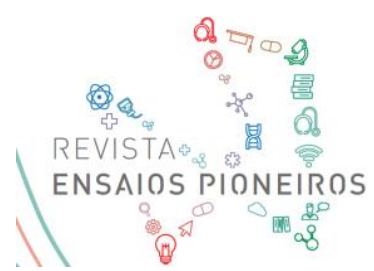

A fim de compreender de maneira mais detida como se desenrola o desenvolvimento do projeto, é válido compreender a sequência didática desenvolvida na matéria de Novas tecnologias na Educação. A mesma principia com discussões acerca da evolução tecnológica que marca nossa época, bem como sobre o que se convencionou chamar de sociedade da informação (CASTELLS \& ESPANHA, 1999). A partir disso, são trabalhados através de diversas dinâmicas pedagógicas em classe os critérios fundamentais que orientam uma boa utilização da tecnologia na Educação, a partir sobretudo do trabalho de Kenski (2015), considerado referência no tema. Tais critérios são, eles mesmos, associáveis às metodologias ativas: a possibilidade de que as novas tecnologias tragam desafios na sala de aula; a sua capacidade de tornar visíveis os elementos abstratos trabalhados; e a perspectiva de que contribuam para a inclusão digital dos estudantes, o que é uma demanda inexorável do mundo atual. Na sequência, é apresentado o software Geogebra (Figura 1), amplamente considerado um instrumento valioso para o ensino da Matemática na Educação Básica por ser capaz de articular as grandezas algébricas com as representações geométricas que se lhe associam, além de possibilitar a exploração rápida das ilustrações imagéticas das relações entre as grandezas quantitativas abordadas (HOHENWARTER \& HOHENWARTER, 2009).

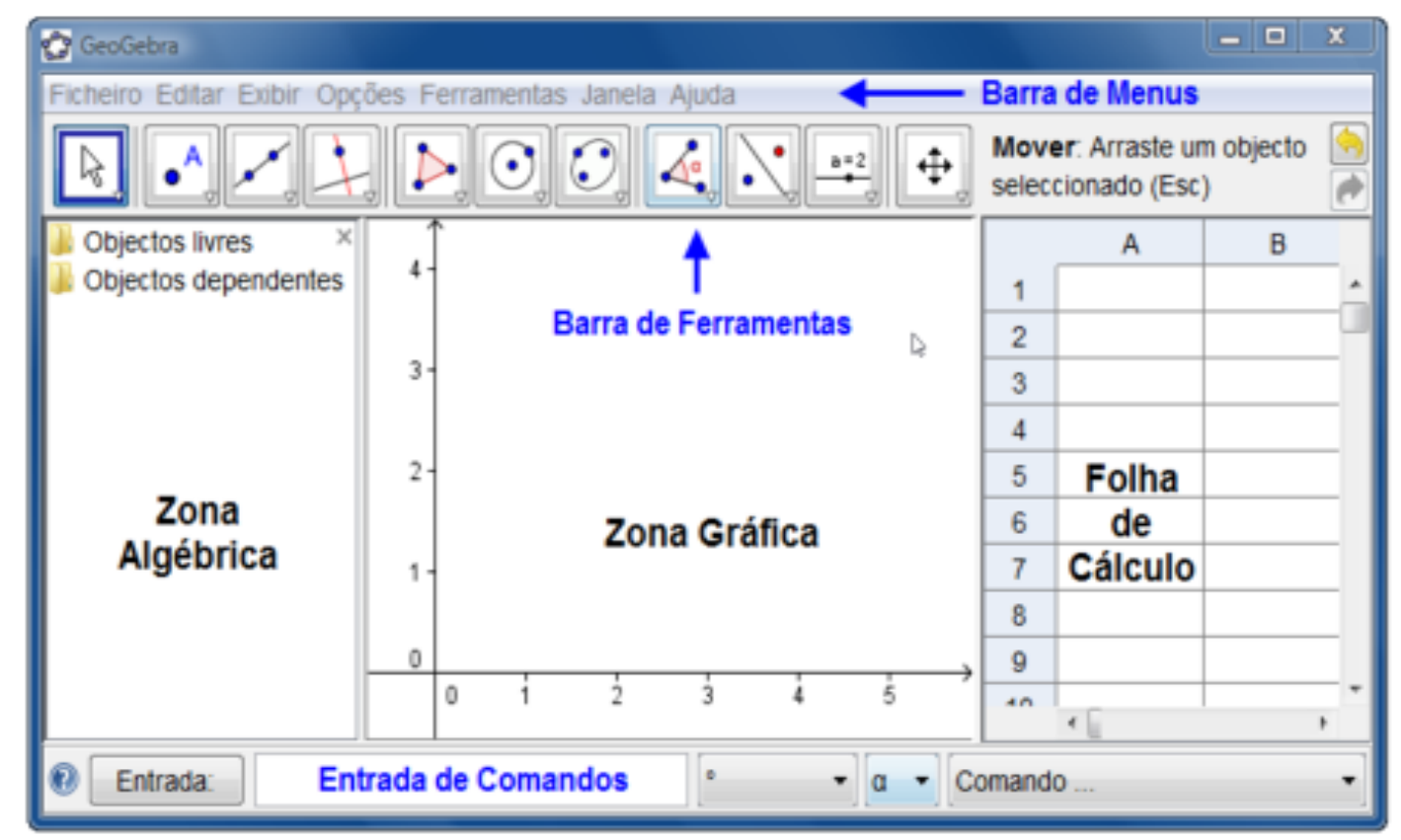

Figura 1 - A interface do Geogebra. Fonte: HOHENWARTER, Markus \& HOHENWARTER, Judith. Ajuda GeoGebra: Manual oficial da versão 3.2. Sl: sn, 2009.

No segundo bimestre, primeiro se busca avaliar a qualidade de práticas pedagógicas realizadas com a utilização do Geogebra e expostas em artigos que são resenhados a partir dos critérios definidos anteriormente; no último mês do semestre é então o momento de colocar em ação os conhecimentos construídos para a materialização do projeto pedagógico. Nesse ponto, é importante salientar que os conteúdos não perdem a importância no contexto das metodologias ativas de ensino: pelo contrário, eles têm a importância decisiva de alicerçar a construção de habilidades e competências específicas que se substancializarão, neste caso em específico, na elaboração do produto final do projeto a partir da situação problema apresentada. Sendo assim, vale apontar quais são os critérios de avaliação dos produtos. Eles se baseiam em 
algumas variáveis específicas: correção formal na construção dos planos de ensino; capacidade de adequar os conteúdos específicos ao contexto da Educação Básica; boa utilização do software educacional para a transmissão do conteúdo escolhido de acordo com os critérios estabelecidos no primeiro bimestre; promoção de situações dialógicas no processo pedagógico a partir da inserção da tecnologia.

Assim podemos concluir que o projeto ancorado na situação problema busca realmente operar com a produção da autonomia do saber ao procurar estabelecer a proposição de um plano de ação para a atuação profissional que conjuga os conteúdos de uma forma em que o produto do módulo é algo que os alunos não apenas guardam, mas socializam no ambiente de interação virtual a fim de que realmente os mesmos possam ser utilizados na sua atuação enquanto egressos.

\section{As situações problema como base para a construção de um projeto didático em grupos no curso de Pedagogia}

O Projeto Integrado do módulo III do curso de Pedagogia online tem por objetivo a elaboração de um Plano Pedagógico para uma sequência didática sobre um determinado conteúdo da Educação Infantil ou do Ensino Fundamental I, de forma que tal plano esteja de acordo com a nova Base Nacional Comum Curricular. A construção desse plano deve se fundamentar em uma situação problema que conjugará elementos das disciplinas de Psicologia da Educação, de Filosofia da Educação e de Educação Ambiental, Sustentabilidade e Responsabilidade Social. Além disso, é requerido que cada grupo elabore um conjunto de atividades avaliativas referentes aos conteúdos e habilidades tematizados pelo Plano Pedagógico, de forma que a disciplina de Estudos de Avaliação desempenhe também um papel preponderante na concepção do trabalho.

A partir da definição de cinco situações problema específicas, que são divididas por sorteio entre os quinze grupos, os alunos devem procurar construir o produto final que será elaborado em face à situação problema correspondente. Mas de que forma tal produto está arquitetado e como os conteúdos, habilidades e competências referentes às diversas disciplinas do módulo se conjugarão em sua realização?

O ponto de partida é a necessária e fundamental compreensão da nova Base Nacional Comum Curricular. Para tanto, foi disponibilizada uma série de vídeos sobre o tema que trazem explicações bastante didáticas sobre as alterações curriculares, vídeos esses elaborados pela professora Dra. Sônia Siquelli, especialista sobre o tema da legislação educacional brasileira e docente da UNIEOB. Dessa forma, a disciplina de Estudo de Currículos e Desafios Contemporâneos é enriquecida por esse material, produzido especificamente para contextualizar as reestruturações curriculares em curso. Mais do que isso, sua compreensão é um ponto de partida para a elaboração do produto, uma vez que é esperado que o Plano Pedagógico apresentado esteja em conformidade com a nova Base Nacional Comum Curricular. Fica evidente então o esforço para integrar os conteúdos das cinco disciplinas do módulo em um todo associado de forma coerente no contexto da prática docente.

Com isso em mente, é então o momento dos grupos se debruçarem sobre a situação problema que lhes tiver sido destinada e buscar elaborar um Plano Pedagógico para um conjunto de aulas de acordo com o que for definido no escopo de tal situação. Cada uma delas traz um contexto específico, no qual é descrita a realidade de uma escola com características próprias no que se refere ao perfil social, econômico e cultural de seus alunos, bem como em relação à sua localização, história e perfil pedagógico. Além disso, a situação problema apresenta 


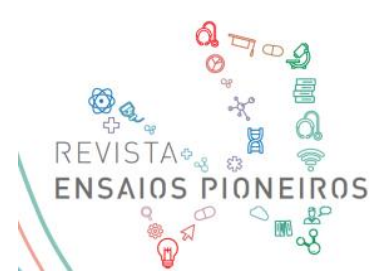

perspectivas teórico-metodológicas próprias as reflexões pedagógicas atinentes às Unidades de estudo de Psicologia da Educação, Filosofia da Educação e (ou) Educação Ambiental, Sustentabilidade e Responsabilidade Social nas quais os Planos Pedagógicos deverão necessariamente se basear. Com o intuito de cumprir então a situação problema proposta, deve ser erigido o Plano Pedagógico - e tal plano é exatamente o produto do Projeto Integrado. Para a realização dos mesmos, prevê-se a utilização da ferramenta wiki, disponível na plataforma Blackboard com a qual operam os cursos online da instituição; tal ferramenta possibilita a edição conjunta de documentos, de forma que os discentes podem trabalhar em grupos mesmo que à distância.

Além disso, como visto acima, é parte integrante do trabalho a necessidade o desenvolvimento de atividades avaliativas relativas aos Planos Pedagógicos. Nesse ponto, é essencial sublinhar que é necessário sempre ter em vista a perspectiva fundamental de que a avaliação é um elemento integrante da prática pedagógica e do processo de ensinoaprendizagem mesmo, e não algo que se dá de maneira posterior, com o intuito único de aferir os níveis de retenção do conteúdo pelos alunos. Dessa forma, é parte importante da produção das atividades avaliativas que cada uma delas contenha explicações gerais sobre como se integram no processo de desenvolvimento cognitivo dos conteúdos e das habilidades a que se referem; ou seja, as atividades avaliativas devem ser acompanhadas de seus objetivos pedagógicos. Esses objetivos podem ser pensados como respostas para uma ou algumas das seguintes questões: como essa atividade estará exercitando o aprendizado dos conteúdos? Qual é o caráter de capacitação, de treinamento das habilidades trabalhadas que esta atividade insere? De que forma ela contribuirá para que os conteúdos trabalhados se integrem ao imaginário, ao cotidiano do aluno? De que maneira essa atividade articulará conteúdos de diferentes naturezas e concorrerá, dessa forma, para a ampliação da visão de mundo do aluno? Vejamos agora as cinco situações problema integrantes do projeto.

\section{Situação Problema 1}

Você é o professor (a) responsável pelo quinto ano do Ensino Fundamental de uma escola da rede municipal de ensino em uma cidade do interior de São Paulo com cerca de 80 mil habitantes. A escola é uma das mais antigas e tradicionais da cidade, sendo comumente vista na comunidade local como a melhor ou uma das melhores instituições educacionais públicas do município. Ela se localiza no centro da cidade e tem um corpo docente composto em sua maior parte por professores experientes e que tendem a seguir uma linha mais tradicional de ensino. Sua classe é composta por alunos pertencentes às classes B, C e D; são inclusos digitalmente e detêm uma cultura geral (um capital cultural) mediana. Em geral, as práticas pedagógicas realizadas fora da sala de aula não são particularmente encorajadas pela instituição, assim como não são comuns as atividades pedagógicas baseadas nas chamadas metodologias ativas, o que pode levar à necessidade de que os alunos sejam familiarizados com as mesmas no caso de sua utilização. Após um semestre com a turma, você chegou à conclusão de que a sala em seu conjunto é pouco sensível as questões ambientais, e vê a necessidade de incluir elementos da Educação Ambiental no conteúdo de Geografia, a fim de conscientizar os alunos sobre importância da qualidade da interação homem-meio ambiente para uma existência mais harmônica com a natureza. O desafio então é: como inserir a temática no conteúdo de Geografia? Como operar pedagogicamente com tal temática no contexto específico em que está inserido(a)? Como despertar o interesse para a importância das questões ambientais? Como alavancar o entendimento das questões próprias às relações homem/meio ambiente no próprio 


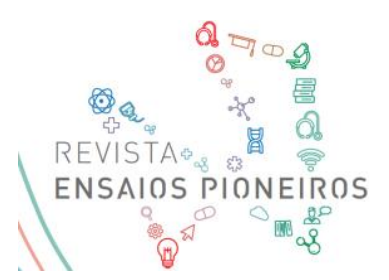

cotidiano no qual estão inseridos? Elabore então um Plano Pedagógico para uma sequência didática que vise atender os objetivos propostos por essas questões.

\section{Situação Problema 2}

Você é o professor (a) de uma turma de pré-escola que conta com alunos na faixa dos cinco anos de idade. Tal escola é particular, localiza-se em uma cidade do interior de São Paulo de porte médio, com cerca de 250 mil habitantes e recebe alunos das classes A e B, sendo considerada de forma geral como uma instituição voltada à elite local. É importante notar que a perspectiva pedagógica da instituição é moderna, voltada às discussões mais recentes da teoria pedagógica e amplamente receptiva no que se refere às práticas didáticas inovadoras e de vanguarda. Especialistas afirmam que a exploração de objetos e materiais concretos é fundamental para um trabalho significativo na Educação Infantil, pois as crianças aprendem a partir dos sentidos. Por isso, garantir variedade nas atividades e materiais pedagógicos é essencial. Tarefas repetitivas, como copiar letras e palavras, não favorecem o aprendizado. A criança precisa de massinha de modelar, papéis para recortar, tintas para pintar, blocos e peças de construção, joguinhos matemáticos e linguísticos, experiências de Ciências e atividades que explorem a psicomotricidade. As brincadeiras são a base do aprendizado na Educação Infantil. Uma parte delas é direcionada, mas, outra boa parte, tem de ser livre, respeitando o ritmo de cada um (ALBUQUERUE, 2015). Com isso em mente, a ideia é que em sua formação profissional você teve muita afinidade com a perspectiva pedagógica construtivista de Jean Piaget e com sua ideia dos estágios de desenvolvimento cognitivo. Dessa forma, sua ideia agora é operar com o construtivismo naquela parcela das atividades lúdicas que serão direcionadas. Uma pesquisa realizada nos EUA acompanhou 1.300 crianças, da maternidade aos doze anos, a cada quatro meses. Metade delas ficou em casa, outra metade foi para a pré-escola. Os dois grupos foram submetidos a testes para avaliar aprendizados: o grupo que frequentava a escola se saiu melhor em todos eles. É possível também perceber a diferença entre crianças que frequentaram a Educação Infantil quando chegam ao Ensino Fundamental. Para especialistas que estudam o assunto, elas são mais sociáveis e apresentam um vocabulário bem mais rico (ALBUQUERUE, 2015). Seu plano para a sequência didática que será trabalhada deve se fundamentar em uma ou algumas práticas que visem favorecer o desenvolvimento linguístico do aluno. A pergunta chave para a elaboração do trabalho seria: como articular práticas lúdicas a partir da noção construtivista de Piaget que sejam enriquecedoras no sentido de desenvolvimento linguístico e de vocabulário das crianças? Além disso, as atividades avaliativas programadas devem ser pensadas muito mais como uma aferição de como as práticas deram ou não resultado de uma forma geral e, claro, como formas de explorar ainda mais a educação construtivista dos alunos - do que como avaliações individuais das crianças. Elabore então um Plano Pedagógico para uma sequência didática que vise atender o objetivo proposto acima.

\section{Situação Problema 3}

Você é professor (a) do quarto ano de um colégio público em uma cidade do interior de São Paulo de cerca de 125 mil habitantes. Trata-se de uma escola da rede municipal de ensino que se localiza na zona limítrofe entre dois bairros: um composto por indivíduos em sua maioria das classes B e C, enquanto o outro possui sobretudo pessoas das classes D e E. Seu grupo de alunos é bastante diversificado, sendo composto por indivíduos de todas as classes sociais 


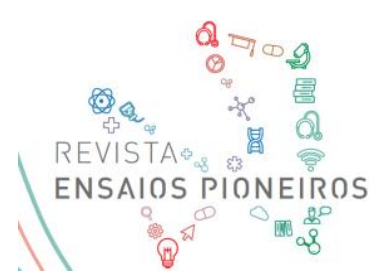

mencionadas, além de possuir etnias e culturas variadas, inclusive com alguns alunos recém advindos de outras cidades em função da mudança dos pais. De forma geral, o grupo de alunos tem um desempenho pedagógico adequado, mas há problemas significativos nas relações entre alguns grupos, de forma que os preconceitos de classe, de etnia e de cultura arraigados em nossa sociedade são patentes em muitas situações cotidianas. Você decide então quer seria fundamental trabalhar uma melhor compreensão do que chamamos de alteridade para que os conflitos decorrentes dos preconceitos fossem amainados; o conteúdo de História do Brasil lhe parece o mais adequado para isso. É fundamental notar que alguns dos conceitos trabalhados durante a Unidade de Pedagogia da Educação são essenciais para se melhor contextualizar as questões envolvidas, como os de vida afetiva, representações sociais e identidade. O seu desafio é então estabelecer um plano para inserir a temática no conteúdo de História: como operar pedagogicamente com tal temática no contexto específico em que está inserido(a)? Como realmente articular um melhor entendimento das diversidades de forma a que elas deixem de ser vistas de forma negativa? Como alavancar o entendimento das questões próprias às relações multiétnicas e multiculturais no contexto mesmo com o qual estão envolvidos os alunos; ou seja, como pensar em tais questões no contexto da cidade e de sua própria formação histórica? Elabore então um Plano Pedagógico para uma sequência didática que vise atender os objetivos propostos por essas questões.

\section{Situação Problema 4}

Você é professor ingressante do quarto ano de uma escola localizada na zona rural de um município de 25 mil habitantes do Estado de São Paulo. Desde sua chegada à instituição, você percebe que os alunos têm uma relação afetiva com a mesma: ter a chance de ir à escola, coisa que a grande maioria de seus pais não tiveram, é motivo de orgulho e júbilo por parte deles. Não obstante, no que se refere ao conteúdo, eles demonstram extrema dificuldade para desenvolver a aprendizagem em função de uma má formação nos anos iniciais de sua educação regular e de um baixo capital cultural adquirido no ambiente familiar. Você decide então elaborar um projeto que visa discutir um tema específico: o de alienação. Tal projeto tem a perspectiva de conjugar conteúdos próprios à História e à Geografia, de forma que a história das desigualdades em nosso país, bem como a dinâmica da organização do espaço rural/urbano sejam matéria prima para a melhor compreensão da realidade na qual a turma se insere. No caso em específico, você não terá que ser reportar detidamente à coordenação da escola sobre o como e o porquê de tal projeto, uma vez que as diretrizes pedagógicas da escola são pouco ou nada pronunciadas, dada a situação de carência na qual a mesma se encontra. Seu grande objetivo aqui é realmente engendrar uma reflexão que sirva para que os alunos concebam melhor a realidade de seu quadro social e adquiram elementos para pensar em alterá-lo para melhor. Nesse sentido, seu plano pedagógico para o projeto deve visar responder às seguintes questões: como reconhecer o conceito de alienação? Como concebê-lo de forma a que ele seja iluminado pela realidade histórica e geográfica de um grupo? Como Identificar os reflexos da alienação na sociedade? Como fazer com que a reflexão sobre a noção de alienação estimule o entendimento sobre o próprio quadro social no qual se está inserido para, a partir daí, pensar em melhorias das condições objetivas de sua própria inserção social? Elabore então um Plano Pedagógico para uma sequência didática que vise atender os objetivos propostos por essas questões. 


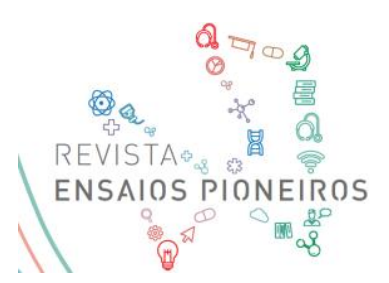

\section{Situação Problema 5}

Você é professor (a) do quinto ano de uma escola pública municipal no interior de São Paulo, em um município de 800 mil habitantes. A realidade de escola é extremamente delicada, uma vez que se encontra em um bairro de periferia bastante violento, no qual o narcotráfico desempenha papel chave. As condições são precárias em todos os sentidos: não existe transporte adequado, há falta de material didático, a estrutura física da escola encontra-se deteriorada, os professores estão desestimulados e temerosos à violência. Nesse contexto, não é de se espantar que a maioria dos alunos possua baixo autoestima e mesmo que grande parte dos mesmos veja a entrada no mundo do crime como a sua melhor possibilidade objetiva de ascender socialmente. Nesse sentido, você se vê na obrigação de contextualizar a realidade com a qual os mesmos se deparam no sentido de ampliar a sua visão de mundo de forma que novas possibilidades sejam vislumbradas e que a realidade do crime e do tráfico deixe de ser vista de maneira atrativa e mesmo glamorosa. Para sua surpresa, em seus primeiros meses de contato com a turma, você percebeu que a leitura e a interpretação de textos é a atividade que mais encontra eco entre os alunos. Muitos deles gostam também de música, sendo que o rap é de forma geral seu gênero favorito. É importante notar que essa situação está associada a uma discussão realizada no âmbito da Psicologia da Educação: a de que que status econômico e realidades conflituosas são geradores da necessidade de práticas específicas em sala de aula. Nesse sentido, você decide tentar trazer novos entendimentos sobre a realidade de violência e desigualdade a partir de práticas de leitura e de escrita. Cabe então decidir como articular essa perspectiva: leituras de textos específicos sobre desigualdade, violência e tráfico de drogas? Quais textos e com quais objetivos? Realização de um concurso de redações a partir de temas específicos? Quais temas e como capacitar os alunos para refletir sobre os mesmos? Desenvolvimento de um pequeno festival de rap entre os alunos? Quais os temas que as músicas devem ter e como devem se posicionar do lado da paz e não da violência? Notem que o grande objetivo da prática é fazer com que os alunos se capacitem para 1) identificar as complexas maneiras pelas quais as tensões e contradições sociais e econômicas se manifestam em sua realidade violenta e precária e 2) descortinar novas possibilidades no horizonte desses alunos que não sejam marcados pelo crime e pela violência. Elabore então um Plano Pedagógico para uma sequência didática que vise atender o objetivo proposto acima.

Os critérios de avaliação dos planos didáticos a serem entregues como produtos da dinâmica são os seguintes: adequação da proposta pedagógica apresentada perante a situação problema exposta; conformidade do plano pedagógico com os temas e conceitos referentes às disciplinas que são dinamizadas por cada uma das situações problemas propostas; pertinência pedagógica das atividades avaliativas desenvolvidas e clareza em seus objetivos referentes ao processo de ensino/aprendizagem; harmonia e colaboração de todos os membros do grupo no sentido de realizar todas as etapas do projeto de forma sinérgica e conjunta.

No que diz respeito a esse último aspecto, é importante salientar novamente que os grupos serão formados a partir de sorteios. Dessa forma, a ideia é exatamente simular uma situação com a qual os profissionais de Educação se deparam constantemente em sua carreira profissional: a necessidade de se trabalhar em grupos com indivíduos com os quais se tem pouco contato, conhece-se pouco e, mesmo, em alguns casos com pessoas com que se tenha pouca afinidade. A ideia é exatamente procurar exercitar essa importante competência atitudinal que é o trabalho em equipe, independente de quem sejam as outras pessoas com as quais se irá operar. De qualquer forma, devido à natureza da atividade, cada grupo tem a liberdade e mesmo 
o dever de procurar o professor orientador do P.I. ou a coordenação dos cursos online para reportar a não participação adequada de um ou de alguns dos seus membros e isso deverá ser compreendido por todos os envolvidos não como problemas de relacionamento interpessoal entre os participantes, mas sim como algo associado às vicissitudes de uma prática pedagógica desenvolvida de maneira coletiva por alguns profissionais da área - o que irá ser uma situação comum na carreira profissional do Pedagogo.

Dessa maneira, a conjugação das aprendizagens baseadas em problemas e em projetos busca encadear de maneira bastante pontuada os conteúdos trabalhados nas diversas disciplinas com uma realidade suposta que pretende espelhar situações reais com as quais os futuros docentes devem se deparar em seu ofício, de modo que realmente tais conteúdos sejam a substância originária de conhecimentos práticos e aptos a possibilitar uma intervenção diferenciada na complexa realidade social e educacional que espera os que optam pela incumbência de ensinar.

\section{CONSIDERAÇÕES FINAIS}

Neste artigo buscamos discutir como as chamadas metodologias ativas do ensino podem ser ferramentas extremamente valiosas para a formação profissional em uma era que as informações estão cada vez mais facilmente disponíveis pela interação com as novas tecnologias. De fato, a ideia do professor enquanto um mero transmissor de conteúdos se tornou ultrapassada no cenário da Educação atual, e é essencial que o docente do nível superior desenvolva estratégias que possibilitem que ele se consolide enquanto um elemento facilitador no processo de construção de habilidades e competências que serão base para a atuação do egresso em sua carreira profissional. Só assim o mesmo poderá realmente se constituir como um protagonista não apenas no processo de ensino e aprendizagem no âmbito da Universidade, mas também em sua inserção do mundo do trabalho. Procuramos evidenciar como duas das estratégias ativas de ensino - a aprendizagem através da resolução de situações problema e a aprendizagem por projetos - podem se articular de maneira significativa e estabelecer um ambiente colaborativo e harmônico nas relações entre professor/tutor e aluno e entre aluno/aluno. Primeiramente, demonstramos como a conjugação das duas metodologias é pertinente conceitualmente e, na sequência, procuramos ilustrar como tal junção foi base para a estruturação de duas práticas pedagógicas desenvolvidas na UNIFEOB: uma no curso presencial de Matemática de Licenciatura e uma no curso online de Pedagogia. Esperamos que as ponderações realizadas aqui possam ser frutíferas no sentido de engendrar mais reflexões a respeito e, quem sabe, mais práticas docentes do ensino superior fundadas na conjugação das duas práticas aqui exploradas.

\section{REFERÊNCIAS}

ALBUQUERQUE, Fátima. Educação Infantil vai além do cuidar. A Tribuna - Jornal Digital do Mato Grosso. Fevereiro de 2015.

BENDER, Willian N. Aprendizagem baseada em projetos: educação diferenciada para o século XXI. Porto Alegre: Penso Editora, 2015.

BERBEL, Neusi Aparecida Navas. As metodologias ativas e a promoção da autonomia de estudantes. Semina: Ciências Sociais e Humanas, v. 32, n. 1, p. 25-40, 2012. 
CASTELLS, Manuel \& ESPANHA, Rita. A era da informação: economia, sociedade e cultura. São Paulo: Paz e terra, 1999.

FREIRE, Paulo. Pedagogia do oprimido. São Paulo: Paz e Terra, 1996.

HOHENWARTER, Markus \& HOHENWARTER, Judith. Ajuda GeoGebra: Manual oficial da versão 3.2. Sl: sn, 2009.

KENSKI, Vani Moreira. Educação e Tecnologias: o novo ritmo da informação. Campinas: Papirus, 2015.

LOVATO, A., YIRULA, C. P. \& FRANZIM, R. (org.). Protagonismo - a potência de ação da comunidade escolar. São Paulo: Alana Editora, 2017.

MAZUR, Eric. Peer instruction: a revolução da aprendizagem ativa. São Paulo: Penso Editora, 2015.

MOREIRA, M. N.; LEMOS, I. M.; SACARMOCIN, M. F. P. Um por todos e todos por um. O que é pedagogia de projetos? Revista Nova Escola, Fundação Victor Civita, edição de maio de 1998.

PERRENOUD, Philippe \& THURLER, Monica Gather. As competências para ensinar no século XXI: a formação dos professores e o desafio da avaliação. Porto Alegre: Artmed Editora, 2009.

RIBEIRO, Luis R. Camargo. Aprendizagem baseada em problema (PBL): uma experiência no ensino superior. São Carlos: Edufscar, 2008.

TOYOHARA, D. Q. K., de SENA, G. J., de ARAÚJO, A. M., \& AKAMATSU, J. I. Aprendizagem Baseada em Projetos - uma nova Estratégia de Ensino para o Desenvolvimento de Projetos. In: PBL - Congresso Internacional. 2010.

Aceito em: 28/09/2018

Publicado em: 10/12/2018 